\title{
Tantalum oxide as filler for dental adhesive resin
}

\author{
Isadora Martini GARCIA, Vicente Castelo Branco LEITUNE, Carolina Jung FERREIRA \\ and Fabricio Mezzomo COLLARES
}

\author{
Dental Materials Laboratory, School of Dentistry, Federal University of Rio Grande do Sul, Rua Ramiro Barcelos, 2492/4 floor, Porto Alegre, RS, \\ Brazil \\ Corresponding author, Vicente Castelo Branco LEITUNE; E-mail: vicente.leitune@ufrgs.br
}

\begin{abstract}
The purpose of this study was to formulate and evaluate an adhesive resin with tantalum oxide. $\mathrm{Ta}_{2} \mathrm{O}_{5}$ was evaluated by scanning electron microscopy and laser diffraction. The adhesive was formulated with methacrylate monomers and photoinitiators. Ta $2 \mathrm{O}_{5}$ was added into the adhesive at $1,2,5$ and $10 \mathrm{wt} \%$. One group remained without filler (control group). Ta $\mathrm{O}_{5}$ distribution, radiopacity $(n=5)$, degree of conversion (DC) $(n=3)$, softening in solvent $(n=5)$ and ultimate tensile strength (UTS) (n=10) were evaluated. Data were analyzed by one-way ANOVA and Tukey's test $(\alpha=0.05)$. Spherical nanometric $\mathrm{Ta}_{2} \mathrm{O}_{5}$ was arranged in $3.35 \mu \mathrm{m}$ particles. The groups over $5 \mathrm{wt} \%$ presented higher radiopacity $(p<0.05)$. The DC ranged from $61.78( \pm 1.19) \%$ to $67.35( \pm 1.40) \%$, with statistical difference from control group over $5 \mathrm{wt} \%$ addition $(p<0.05)$. There was no difference in softening in solvent $(p>0.05)$ and UTS $(p>0.05)$. Tantalum oxide is a promising alternative for adhesive formulation and it could be further tested for biomimetic remineralization.
\end{abstract}

Keywords: Dental cements, Inorganic compounds, Tantalum oxide

\section{INTRODUCTION}

The wet environment of the dentin is adverse for the polymerization of methacrylate monomers, promoting an interface susceptible to degradation over time ${ }^{1,2}$. In addition, an adequate cavity seal is necessary to inactivate the residual bacteria in affected dentin to stop caries progress in a minimally invasive dentistry approach ${ }^{3)}$. Many modifications have been proposed in the adhesive resins to contribute to the longevity of the restorative treatments ${ }^{4-6)}$. A current trend involves the incorporation of inorganic fillers to decrease the relative amount of organic phase, providing a higher hydrolytic stability to resin and a reliable cavity seal ${ }^{7-12}$.

Besides physical and chemical properties, the addition of inorganic fillers may increase the radiopacity. A radiopaque adhesive resin promotes more accurate diagnosis by clinicians and the distinction of recurrent caries from restorative material ${ }^{13)}$. The most used filler in commercial adhesives is silicon dioxide (either colloidal silica or pyrogenic silica) ${ }^{14)}$. However, silica is radiolucent and must be supplemented with metalcontaining glasses or minerals to be radiopaque ${ }^{14,15}$. Nevertheless, glasses are susceptible to hydrolysis and degradation. To eliminate the use of glasses, one solution is to use heavy-atom compound as homogeneous filler in matrix ${ }^{15}$. Ytterbium trifluoride $\left(\mathrm{YbF}_{3}\right)^{11)}$, barium sulphate $\left(\mathrm{BaSO}_{4}\right)$, calcium tungstate $\left(\mathrm{CaWO}_{4}\right)^{16)}$ and niobium pentoxide $\left(\mathrm{Nb}_{2} \mathrm{O}_{5}\right)^{8,10)}$ have been used. However, the incorporation of the inorganic filler needs to be in low concentrations in order to not compromise the wetting of the dental substrate due to high viscosity of the resin while it is possible to increase the radiopacity and mechanical properties of the material ${ }^{14)}$.

Tantalum is known to be a radiopaque element ${ }^{17)}$ and a biocompatible material ${ }^{10,18)}$. Furthermore, tantalum metal showed bioactivity ${ }^{19,20)}$ and affinity to phosphate groups ${ }^{21)}$, enabling the deposition and nucleation of apatite on its surface. Tantalum oxide also showed bioactivity, inducing hydroxyapatite growth and osteoblasts attachment ${ }^{21}$. Tantalum oxide and metal alloys with tantalum have been used in medicine ${ }^{18)}$ and in dental fields ${ }^{22-26)}$ due to properties as high fracture toughness and high workability ${ }^{20)}$. Therefore, it has been studied and it was incorporated in polymer-based materials to dentistry ${ }^{15,27}$. However, to the best of our knowledge, there are no reports on the use of pure tantalum oxide $\left(\mathrm{Ta}_{2} \mathrm{O}_{5}\right)$ in adhesive resins. The purpose of this study is to develop an experimental adhesive resin with $\mathrm{Ta}_{2} \mathrm{O}_{5}$ in different concentrations and evaluate the radiopacity, degree of conversion (DC) and ultimate tensile strength (UTS) of the formulated adhesive resin.

\section{MATERIALS AND METHODS}

Morphological analysis of $\mathrm{Ta}_{2} \mathrm{O}_{5}$

The morphological analysis of tantalum oxide was performed by scanning electron microscopy (SEM) (JSM 6060, JEOL, Tokyo, Japan). The powder of $\mathrm{Ta}_{2} \mathrm{O}_{5}$ was placed on metallic stubs and gold-sputter coated (15$25 \mathrm{~nm}$ ) (SDC 050, Baltec, Vaduz, Liechtenstein). The equipment was configured to $8 \mathrm{kV}, 10,000$ and 20,000x magnification.

Particle size of $\mathrm{Ta}_{2} \mathrm{O}_{5}$

The particles of tantalum oxide was dispersed in ultrasound for $10 \mathrm{~s}$ with isopropyl alcohol before the analysis. Particle size was assessed by laser diffraction (CILAS 1180, Cilas, Orleans, France) according to previous study ${ }^{28}$. 


\section{Experimental adhesive resin formulation}

The experimental adhesive resin was formulated mixing 50 wt\% bisphenol-A-glycidyl methacrylate (Bis-GMA), 25 wt\% triethyleneglycol dimethacrylate (TEGDMA) and $25 \mathrm{wt} \%$ 2-hydroxyethyl methacrylate (HEMA). Camphorquinone (CQ) and ethyl 4-dimethylaminobenzoate (EDAB) were added as photoinitiator system at $1 \mathrm{~mol} \%$ to all groups, according to monomer moles and $0.01 \mathrm{wt} \%$ Butylated hydroxytoluene (BHT). All these materials were provided by Aldrich Chemical (St Louis, MO, USA). $\mathrm{Ta}_{2} \mathrm{O}_{5}$ was subjected to a silanisation process with $5 \%$ of silane $(\gamma$-methacrylo xypropyltrimethoxysilane, Aldrich Chemical) and 95\% of solvent (acetone), in weight. After the silanisation process, the particles were stored for $24 \mathrm{~h}$ at $37^{\circ} \mathrm{C}$ to allow the solvent vaporization. $\mathrm{Ta}_{2} \mathrm{O}_{5}$ powder was added at four different concentrations: 1, 2, 5 and $10 \mathrm{wt} \%$ into the adhesive resin and one group remained without filler addition as control group. All the components were weighed using an analytical balance (AUW220D, Shimadzu, Kyoto, Japan).

The mixture (resin/particles) was hand-mixed for $5 \mathrm{~min}$, sonicated for $180 \mathrm{~s}$ and hand-mixed again for 5 min. To perform monomer photo-activation, a lightemitting diode unit (Radii Cal, SDI, Victoria, Australia) was used. An irradiation value of $1,200 \mathrm{~mW} / \mathrm{cm}^{2}$ was confirmed with a digital power meter (Ophir Optronics, North Andover, MA, USA).

\section{Particle distribution analysis}

Adhesive resin was inserted into a cylindrical silicon matrix with $5 \mathrm{~mm}$ of diameter, covered by a polyester film and photo-activated (Radii Cal, SDI) for $30 \mathrm{~s}$ on each side. The specimens $(n=1)$ were placed on metallic stubs and gold-sputter coated (15-25 nm) (SDC 050, Baltec). The distribution of the $\mathrm{Ta}_{2} \mathrm{O}_{5}$ particles in the polymer was analyzed by SEM (JSM 6060, JEOL) using $3 \mathrm{kV}$.

\section{Radiopacity}

The radiopacity of adhesive resins was evaluated according to International Organization of Standardization (ISO) 4049/2009 standards. Five specimens were produced per group $(n=5), 10.0 \mathrm{~mm}( \pm 0.5$ $\mathrm{mm})$ in diameter and $1.0 \mathrm{~mm}( \pm 0.1 \mathrm{~mm})$ in thickness each one. Radiographic images were obtained using a phosphor plate digital system (VistaScan, Dürr Dental, Bietigheim-Bissingen, Germany) at $70 \mathrm{kV}$ and $8 \mathrm{~mA}$, with $0.4 \mathrm{~s}$ of exposure time and a focus-film distance of $400 \mathrm{~mm}$. For each film, one specimen from each concentration was positioned, for a total of five specimens per film. An aluminium step-wedge was exposed simultaneously with the specimens in all images. The aluminium step-wedge thickness ranged from 0.5 to $5.0 \mathrm{~mm}$ in increments of $0.5 \mathrm{~mm}$. The aluminium alloy used was $\mathrm{Al}$ 99.12, Fe $0.47, \mathrm{Mg} 0.41$ and with $<0.1$ of $\mathrm{Cu}$ (mass\%). The images were saved in TIFF format and analyzed using Photoshop software (Adobe Systems Incorporated, San Jose, CA, USA). The mean and standard deviation of the grey levels (pixel density) was measured according to previous study ${ }^{7}$.
$D C$

DC of adhesive resins was measured by fourier transform infrared spectroscopy (FTIR) with a spectrometer (Vetrex 70, Bruker Optics, Ettingen, Germany) equipped with an attenuated total reflectance device (ATR), composed of a horizontal diamond crystal with a mirror angle of 45 degrees. A support was coupled to the spectrometer fixing the light-curing unit and standardizing the distance between the fiber tip and sample in $5 \mathrm{~mm}$. Data was evaluated with the Opus software (Bruker Optics), with Blackman-Harris 3-Term apodization in a range of 4,000 to $400 \mathrm{~cm}^{-1}$ and a resolution of $4 \mathrm{~cm}^{-1}$. The sample (uncured composite) ( $n=3)$ was directly dispensed on the top of the diamond crystal and photoactivated for $20 \mathrm{~s}$. The analyses were performed in a room at $23^{\circ} \mathrm{C}$ and $60 \%$ relative humidity. The absorbance spectra were obtained before and after polymerization. The DC was calculated as showed in a previous study ${ }^{28)}$.

\section{Softening in solvent}

Samples (5.0 $\mathrm{mm}$ in diameter and $1.0 \mathrm{~mm}$ thick) were prepared of each experimental adhesive resin $(n=5)$ and light activated for $30 \mathrm{~s}$ on each side. The specimens was polished before Knoop microhardness (KHN) measurements. Three indentations were made (10 g for $5 \mathrm{~s}$ ) in each specimen (HMV 2, Shimadzu) before (KHN1) and after immersion in a solution of $50 \%$ ethanol and $50 \%$ water mixture for $2 \mathrm{~h}$ (KHN2). The percentage difference between KHN1 and the KHN2 values were calculated ( $\triangle \mathrm{KHN} \%)$.

\section{UTS}

The adhesive resins were dropped into a metallic matrix with a hourglass design measuring $8 \mathrm{~mm}$ long, $2 \mathrm{~mm}$ wide, $1 \mathrm{~mm}$ thick and a cross-sectional area of $1 \mathrm{~mm}^{2}$ and were covered with polyester matrix on both sides before light activation. All specimens were light activated for $30 \mathrm{~s}$ on each side, after polymerization, specimens were measured with a digital caliper. Hourglass shaped specimens $(n=10)$ were fixed in a specific device with cyanoacrylate adhesive and loaded under tension. Tests were performed in a test machine Shimadzu (EZ-SX; Shimadzu) at a crosshead speed of $1-\mathrm{mm} / \mathrm{min}$. UTSs were calculated according to previous study ${ }^{29)}$.

\section{Statistical analysis}

The normality of data was evaluated using the ShapiroWilktest. Statistical data analysis was performed using one-way ANOVA and Tukey's test at the 0.05 level of significance $(p<0.05)$ and paired student's $t$-tests were performed between KNH1 and KNH2.

\section{RESULTS}

The morphology of tantalum oxide is shown in Fig. 1. Nanometric tantalum oxide particles with spherical shape arranged in agglomerates were observed. The analysis of particle size of $\mathrm{Ta}_{2} \mathrm{O}_{5}$ by laser diffraction showed a median size of $3.35 \mu \mathrm{m}$. Images of distribution of the tantalum oxide particles in the polymer are presented in Fig. 2. The 

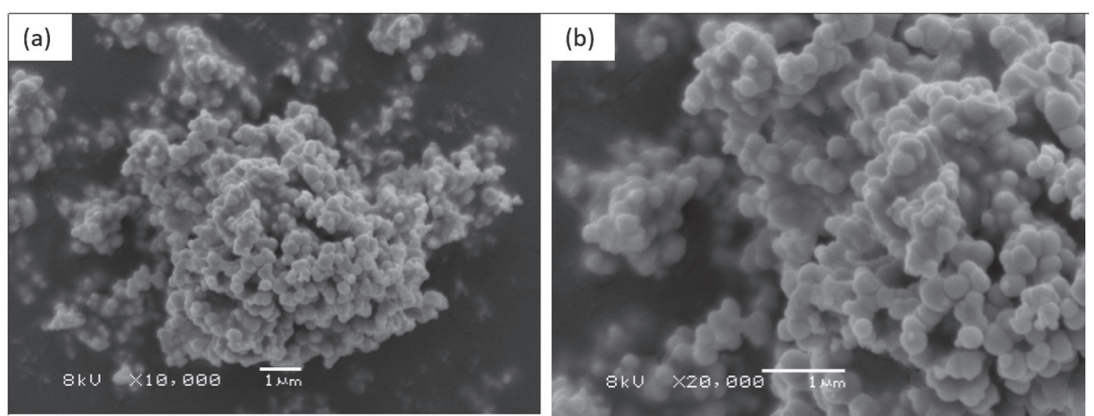

Fig. 1 Representative image of tantalum oxide.

Tantalum oxide particles have 300 nanometers size, spherical shape and are clustered in agglomerates of 5 micrometers.
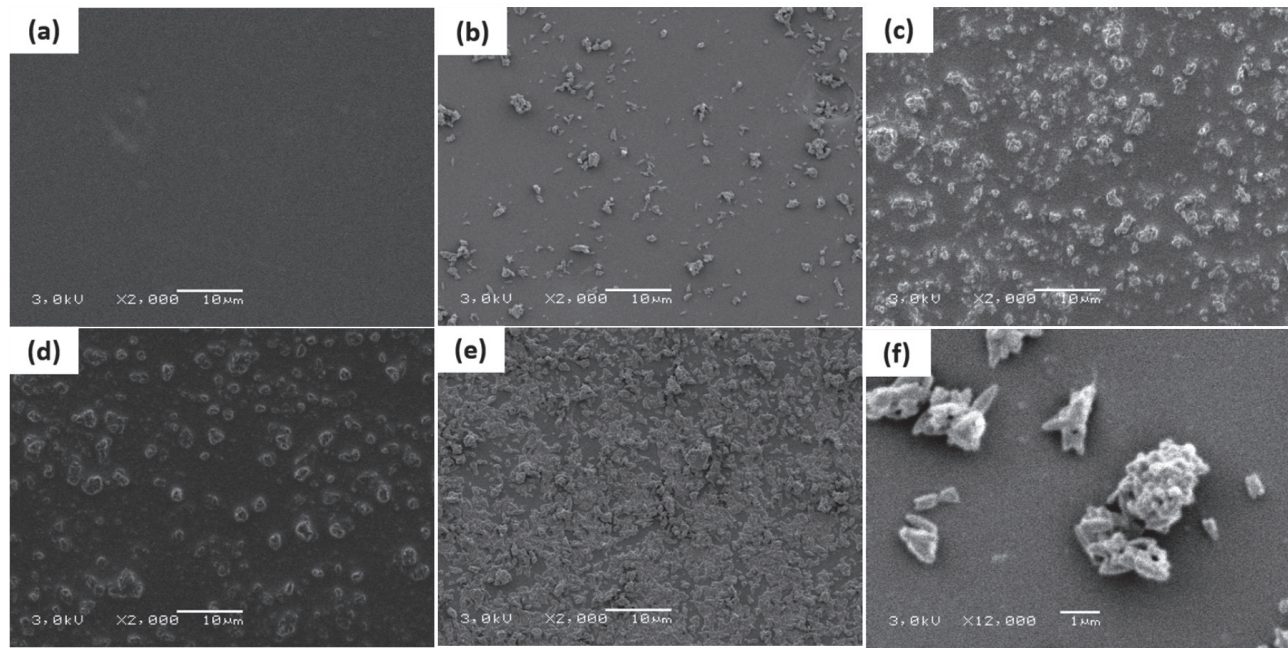

Fig. 2 Distribution of the tantalum oxide particles in the polymer.

a: Control group; b: $1 \%$ of $\mathrm{Ta}_{2} \mathrm{O}_{5}$; c: $2 \%$ of $\mathrm{Ta}_{2} \mathrm{O}_{5}$; d: $5 \%$ of $\mathrm{Ta}_{2} \mathrm{O}_{5}$; e: $10 \%$ of $\mathrm{Ta}_{2} \mathrm{O}_{5}$; f:

Agglomerate of the tantalum nanoparticles of about 3 micrometers.

radiopacity values of the experimental dental adhesives are presented in Fig. 3. The density of pixels ranged from $26.06( \pm 3.55)$ to $50.15( \pm 4.97)$. The groups with 5 and $10 \mathrm{wt} \%$ of $\mathrm{Ta}_{2} \mathrm{O}_{5}$ showed higher radiopacity than the control group $(p<0.05)$. A representative image of the radiopacity of all groups is presented in Fig. 4. The DC of the experimental dental adhesives are shown in Table 1 , values ranged from $61.78( \pm 1.19)$ to 69.96 $( \pm 18.67)$. There was no statistically significant difference between control and groups with until 2 wt\% of $\mathrm{Ta}_{2} \mathrm{O}_{5}$ $(p>0.05)$. A representative image of FTIR spectra from adhesive before and after the photoactivation is shown in Fig. 5. Softening in solvent results are demonstrated in Table 2. The initial microhardness values (KNH1) were similar to the control group $(p>0.05)$. The values after immersion in ethanol were lower than the initial ones for all groups $(p<0.05)$. The percentage difference between KHN1 and KHN2 ( $\mathrm{KHN} \%)$ showed no statistically significant difference between all groups $(p>0.05)$. Data of UTS ranged from $57.73( \pm 14.67)$ to $65.15( \pm 18.67)$,

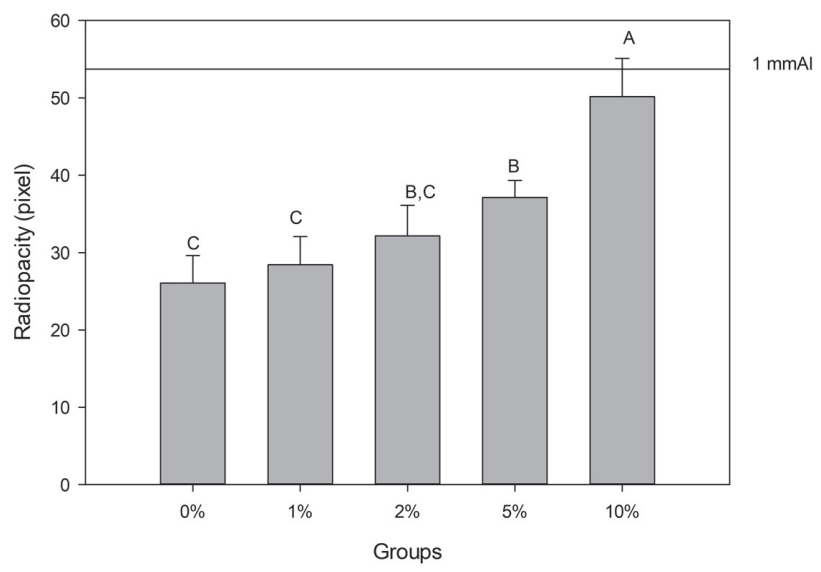

Fig. 3 Means and standard deviations of radiopacity values, in pixels, for dental adhesive resins. The reference line shows the radiopacity, in pixels, for $1 \mathrm{~mm} \mathrm{Al}$. Different capital letter indicates statistical difference $(p<0.05)$. 


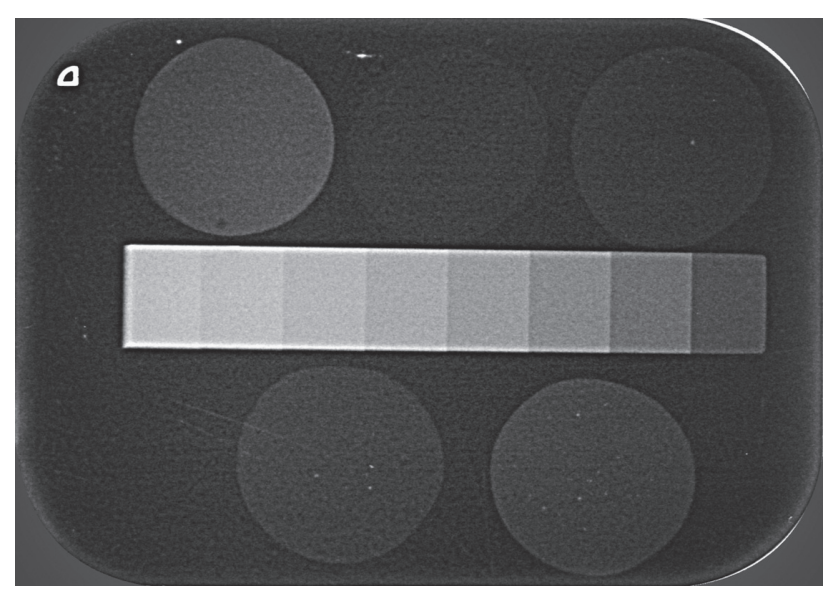

Fig. 4 The X-ray images showing the difference of the radiopacity between groups.

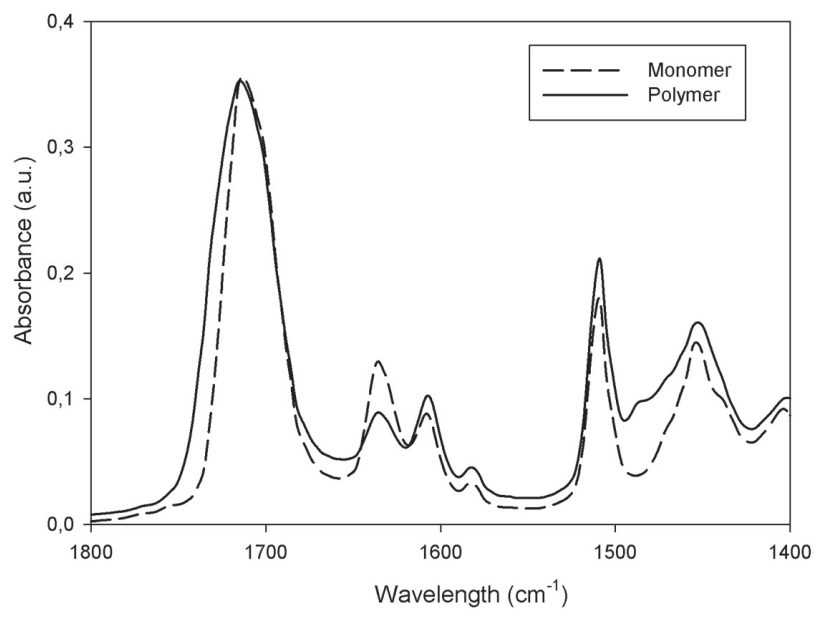

Fig. 5 The FTIR spectra images of DC of polymers. The DC is determined by variation of peaks corresponding to aliphatic $\left(1,640 \mathrm{~cm}^{-1}\right)$, aromatic $\left(1,610 \mathrm{~cm}^{-1}\right)$ bonds of the monomer and de polymer.

Table 1 Means and standard deviations of DC and UTS of adhesive resins

\begin{tabular}{ccc}
\hline Groups & DC $(\%)$ & UTS $(\mathrm{MPa})$ \\
\hline $0 \%$ & $69.96( \pm 18.67)^{\mathrm{A}}$ & $65.15( \pm 18.67)^{\mathrm{A}}$ \\
$1 \%$ & $67.35( \pm 1.40)^{\mathrm{A}, \mathrm{B}}$ & $57.73( \pm 14.67)^{\mathrm{A}}$ \\
$2 \%$ & $65.16( \pm 1.50)^{\mathrm{A}, \mathrm{B}}$ & $62.03( \pm 11.47)^{\mathrm{A}}$ \\
$5 \%$ & $61.82( \pm 4.21)^{\mathrm{B}}$ & $61.67( \pm 14.47)^{\mathrm{A}}$ \\
$10 \%$ & $61.78( \pm 1.19)^{\mathrm{B}}$ & $58.43( \pm 11.07)^{\mathrm{A}}$ \\
\hline
\end{tabular}

Different capital letters indicate statistical difference in the same column $(p<0.05)$.

Table 2 Microhardness value of the model adhesives before (KHN1) and after immersion in solvent (KHN2) and the variation of microhardness values $(\Delta \mathrm{KHN} \%)$

\begin{tabular}{cccc}
\hline & KHN1 & KHN2 & $\Delta$ KHN\% \\
\hline $0 \%$ & $18.10( \pm 0.97)^{\mathrm{Aa}}$ & $7.52( \pm 0.73)^{\mathrm{b}}$ & $58.32( \pm 4.80)^{\mathrm{A}}$ \\
$1 \%$ & $18.44( \pm 2.57)^{\mathrm{Aa}}$ & $10.62( \pm 1.01)^{\mathrm{b}}$ & $41.15( \pm 12.61)^{\mathrm{A}}$ \\
$2 \%$ & $20.42( \pm 2.04)^{\mathrm{Aa}}$ & $10.42( \pm 1.99)^{\mathrm{b}}$ & $48.42( \pm 10.83)^{\mathrm{A}}$ \\
$5 \%$ & $20.18( \pm 1.56)^{\mathrm{Aa}}$ & $11.38( \pm 2.26)^{\mathrm{b}}$ & $43.26( \pm 12.07)^{\mathrm{A}}$ \\
$10 \%$ & $20.06( \pm 1.32)^{\mathrm{Aa}}$ & $10.90( \pm 0.72)^{\mathrm{b}}$ & $45.38( \pm 6.28)^{\mathrm{A}}$ \\
\hline
\end{tabular}

Different capital letter indicates statistical difference in same column $(p<0.05)$. Different small letter indicates statistical difference in same row $(p<0.05)$.

and showed no statistically significant difference among groups ( $p>0.05$, Table 1$)$.

\section{DISCUSSION}

The incorporation of inorganic fillers into polymers may enhance adhesives' mechanical properties and improve the clinical practice ${ }^{5,7-11)}$. It decreases the composite's organic phase and the adhesives may be more hydrolytic stable, as the water sorption occurs mainly in the organic matrix ${ }^{29)}$. The adhesive resin must promote the distinction of the demineralized tissue (dentin or 
enamel) and the restorative material ${ }^{1,9)}$. The addition of radiopaque fillers to adhesives should enable the assessment on radiographs without compromising the material properties ${ }^{11}$.

The tantalum oxide particles were silanized with $5 \%$ silane ( $\gamma$-methacryloxypropyltrimethoxysilane) and $95 \%$ solvent (acetone). Although there is no chemical silanization, the modification of filler surface can affect the rheology of the mixture, improving the wetting of the particles by the resin matrix ${ }^{30,31}$. The analysis of particle size of $\mathrm{Ta}_{2} \mathrm{O}_{5}$ was performed by laser diffraction, which showed a median size of $3.35 \mu \mathrm{m}$. However, it was observed by SEM that the particles presented nanometric size of about $300 \mathrm{~nm}$ and were arranged in bigger particles. The laser diffraction analysis showed the size of nanoparticle agglomerates while with SEM analysis it was possible to observe not only the morphology, but also the arrangement of $\mathrm{Ta}_{2} \mathrm{O}_{5}$. Nanoparticles are prone to agglomeration due to the increase in the surface energy ${ }^{29}$. Although the nanoparticles's agglomeration demonstrated also in the polymers, there was no difference in the mechanical property evaluated by UTS or in the softening in solvent among the experimental groups.

Tantalum is a transition metal with high atomic number (73), factor involved in the radiopacity of the material. Since adhesive resins are made of organic compounds, there is a gap in the commercial adhesive formulations regarding to radiopacity. In this study, from $5 \mathrm{wt} \%$ there was significant difference from control group $(p<0.05)$, an adhesive resin similar to commercial adhesives ${ }^{14)}$. With this amount, the radiopacity achieved $1 \mathrm{~mm} \mathrm{Al}$, value comparable to $1 \mathrm{~mm}$ of sound dentin ${ }^{32}$. Adhesives with higher radiopacity may support the clinician the observation of recurrent caries and restoration failures, improving the accuracy of diagnostics ${ }^{15}$. To replace the use of glasses in adhesive resins, tantalum oxide could be a heavy-metal alternative since it showed to enhance the radiodensity of the experimental adhesive resin.

The DC of the aliphatic carbon double bonds to carbon single bonds is related to improving the properties of the polymer ${ }^{33,34}$. The addition of 5 and 10 wt $\%$ of $\mathrm{Ta}_{2} \mathrm{O}_{5}$ influenced the DC compared to control group $(p<0.05)$. However, all groups showed values above $50 \%$, which is in agreement with the DC of the commercial adhesives in the literature ${ }^{35,36)}$. The addition of fillers in an adhesive resin may change the $\mathrm{DC}^{37}$, due to the decrease of light transmission in the filled resin matrix. Thus, the availability of light in the resin matrix decreased because of the higher refractive index of the filler $(2.09-2.15)^{38)}$ than the co-monomer blend (1.471.59 for monomer and 1.50-1.62 for polymer) ${ }^{8)}$, leading to lower DC of the adhesive resin ${ }^{39}$. Probably it explains the statistically significant difference observed when 5 and $10 \mathrm{wt} \%$ of $\mathrm{Ta}_{2} \mathrm{O}_{5}$ was incorporated. Although, the higher concentrations achieved satisfactory DC, the viscosity of the material may change due to filler addition and microtensile bond strength test is necessary to be accomplished.
Initial hardness values showed no statistical difference between groups, and all groups showed a statistical reduction after solvent immersion. A reduction of DC can influence the values of microhardness ${ }^{40)}$, however the $\Delta \mathrm{KHN} \%$ values showed no statistical difference in all groups, despite reduction of $\mathrm{DC}$ in the addition of 5 and $10 \mathrm{wt} \%$ of $\mathrm{Ta}_{2} \mathrm{O}_{5}$. This may have occurred due to the secondary interactions and cross-linking present in this materials that improve the microhardness, despite the difference of the number of $\mathrm{C}=\mathrm{C}$ converted ${ }^{40}$. With the addition of inorganic fillers there is a reduction of forces of attraction between polymer chains and solvent molecules ${ }^{29}$. Thus, the addition of $\mathrm{Ta}_{2} \mathrm{O}_{5}$ can be improved material properties and the softening resistance, due to the inorganic fillers are less vulnerable to degradation than organic matrix $^{41)}$.

The incorporation of fillers in adhesive resin may increase of the $\mathrm{UTS}^{37,42}$ by decreasing the cracks propagation ${ }^{43)}$ providing obstacles at the crack front ${ }^{37}$. However, the particle clustering formation may occur and it can potentially act as stress concentration site leading to a significant decrease in bond strength ${ }^{39}$. In this study, through increasing concentration of $\mathrm{Ta}_{2} \mathrm{O}_{5}$ to $10 \mathrm{wt} \%$, there was no difference in UTS values for all groups $(p>0.05)$. Thus, the addition up to $10 \mathrm{wt} \%$ was not enough to increase this propertie but it did not produce stress concentration sites, which may improve the performance of the material face to hydrolytic degradation and microtensile bond strength in future studies.

Tantalum oxide is a radiopaque inorganic filler with low toxicity ${ }^{10,18}$ and bioactivity ${ }^{21}$. These properties are very important once the adhesive resin has directly contact with mineralized tissues (dentin and enamel). Therefore, the experimental adhesive resins with $\mathrm{Ta}_{2} \mathrm{O}_{5}$ are suitable for further tests of bioactivity and biomimetic remineralization of collagen fibers and may be an alternative material to be used after selective caries removal.

\section{CONCLUSIONS}

In the present study, the addition of 5 and $10 \mathrm{wt} \%$ of $\mathrm{Ta}_{2} \mathrm{O}_{5}$ into an experimental adhesive resin increased the radiopacity $(p<0.05)$ and remained the $\mathrm{DC}$ compatible with commercial adhesives in literature, maintaining the UTS of the material $(p>0.05)$, the initial microhardness $(p>0.05)$ and the softening in solvent $(p>0.05)$ of the adhesives. Thus, $\mathrm{Ta}_{2} \mathrm{O}_{5}$ up to $10 \mathrm{wt} \%$ showed to be a reliable filler for adhesive resins according to the tested properties. Therefore, tantalum oxide is a promising alternative for adhesive formulation and it could be further tested for biomimetic remineralization.

\section{ACKNOWLEDGMENTS}

The authors gratefully acknowledge CAPES (Coordenação de Aperfeiçoamento de Pessoal de Nível Superior) for the scholarship (Garcia, IM) and the 
CMM (Centro de Microscopia e Microanálise) of Federal Universaty of Rio Grande do Sul for the availability of the use of SEM. The authors declare no potential conflicts of interest with respect to the authorship and/ or publication of this study.

\section{REFERENCES}

1) Salz U, Bock T. Adhesion performance of new hydrolytically stable one-component self-etching enamel/dentin adhesives. J Adhes Dent 2010; 12: 7-10.

2) Breschi L, Mazzoni A, Ruggeri A, Cadenaro M, Di Lenarda R, De Stefano Dorigo E. Dental adhesion review: aging and stability of the bonded interface. Dent Mater 2008; 24: 90101.

3) Maltz M, Henz SL, de Oliveira EF, Jardim JJ. Conventional caries removal and sealed caries in permanent teeth: a microbiological evaluation. J Dent 2012; 40: 776-782.

4) Centenaro CC, Rostirolla FV, Leitune VC, Parolo CF, Ogliari FA, Samuel SM, Collares FM. Influence of addition of 2-[3(2H-benzotriazol-2-YL)-4-hydroxyphenyl] ethyl methacrylate to an experimental adhesive system. Acta Odontol Latinoam 2015; 28: 72-78.

5) Peumans M, De Munck J, Mine A, Van Meerbeek B. Clinical effectiveness of contemporary adhesives for the restoration of non-carious cervical lesions. A systematic review. Dent Mater 2014; 30: 1089-1103.

6) Reis A, Carrilho M, Breschi L, Loguercio AD. Overview of clinical alternatives to minimize the degradation of the resindentin bonds. Oper Dent 2013; 38: E1-E25.

7) Leitune VC, Collares FM, Trommer RM, Andrioli DG, Bergmann CP, Samuel SM. The addition of nanostructured hydroxyapatite to an experimental adhesive resin. J Dent 2013; 41: 321-327.

8) Leitune VC, Collares FM, Takimi A, de Lima GB, Petzhold CL, Bergmann CP, Samuel SM. Niobium pentoxide as a novel filler for dental adhesive resin. J Dent 2013; 41: 106-113.

9) Schulz H, Schimmoeller B, Pratsinis SE, Salz U, Bock T. Radiopaque dental adhesives: dispersion of flame-made Ta2O5/SiO2 nanoparticles in methacrylic matrices. J Dent 2008; 36: 579-587.

10) Leitune VC, Takimi A, Collares FM, Santos PD, Provenzi C, Bergmann CP, Samuel SM. Niobium pentoxide as a new filler for methacrylate-based root canal sealers. Int Endod J 2013; 46: 205-210.

11) Collares FM, Ogliari FA, Lima GS, Fontanella VR, Piva E, Samuel SM. Ytterbium trifluoride as a radiopaque agent for dental cements. Int Endod J 2010; 43: 792-797.

12) Meincke DK, Ogliari Ade O, Ogliari FA. Influence of different fillers on the properties of an experimental vinyl polysiloxane. Braz Oral Res 2016; 30: 1-10.

13) Mjor IA. Clinical diagnosis of recurrent caries. J Am Dent Assoc 2005; 136: 1426-1433.

14) Van Landuyt KL, Snauwaert J, De Munck J, Peumans M, Yoshida Y, Poitevin A, Coutinho E, Suzuki K, Lambrechts P, Van Meerbeek B. Systematic review of the chemical composition of contemporary dental adhesives. Biomaterials 2007; 28: 3757-3785.

15) Chan DC, Titus HW, Chung KH, Dixon H, Wellinghoff ST, Rawls HR. Radiopacity of tantalum oxide nanoparticle filled resins. Dent Mater 1999; 15: 219-222.

16) Collares FM, Klein M, Santos PD, Portella FF, Ogliari F, Leitune VC, Samuel SM. Influence of radiopaque fillers on physicochemical properties of a model epoxy resin-based root canal sealer. J Appl Oral Sci 2013; 21: 533-539.

17) Khalil I, Naaman A, Camilleri J. Properties of tricalcium silicate sealers. J Endod 2016; 42: 1529-1535.

18) Mohandas G, Oskolkov N, McMahon MT, Walczak P, Janowski
M. Porous tantalum and tantalum oxide nanoparticles for regenerative medicine. Acta Neurobiol Exp (Wars) 2014; 74: 188-196.

19) Miyazaki T, Kim HM, Miyaji F, Kokubo T, Kato H, Nakamura T. Bioactive tantalum metal prepared by $\mathrm{NaOH}$ treatment. J Biomed Mater Res 2000; 50: 35-42.

20) Miyaza T, Kim HM, Kokubo T, Ohtsuki C, Kato H, Nakamura T. Mechanism of bonelike apatite formation on bioactive tantalum metal in a simulated body fluid. Biomaterials 2002; 23: 827-832.

21) Maho A, Detriche S, Delhalle J, Mekhalif Z. Sol-gel synthesis of tantalum oxide and phosphonic acid-modified carbon nanotubes composite coatings on titanium surfaces. Mater Sci Eng C Mater Biol Appl 2013; 33: 2686-2697.

22) Pypen CM, Plenk H Jr, Ebel MF, Svagera R, Wernisch J. Characterization of microblasted and reactive ion etched surfaces on the commercially pure metals niobium, tantalum and titanium. J Mater Sci Mater Med 1997; 8: 781-784.

23) Bobyn JD, Stackpool GJ, Hacking SA, Tanzer M, Krygier JJ. Characteristics of bone ingrowth and interface mechanics of a new porous tantalum biomaterial. J Bone Joint Surg Br 1999; 81: 907-914.

24) Levine BR, Sporer S, Poggie RA, Della Valle CJ, Jacobs JJ. Experimental and clinical performance of porous tantalum in orthopedic surgery. Biomaterials 2006; 27: 4671-4681.

25) Bencharit S, Byrd WC, Altarawneh S, Hosseini B, Leong A, Reside G, Morelli T, Offenbacher S. Development and applications of porous tantalum trabecular metal-enhanced titanium dental implants. Clin Implant Dent Relat Res 2014; 16: 817-826.

26) Kim DG, Huja SS, Tee BC, Larsen PE, Kennedy KS, Chien $\mathrm{HH}$, Lee JW, Wen HB. Bone ingrowth and initial stability of titanium and porous tantalum dental implants: a pilot canine study. Implant Dent 2013; 22: 399-405.

27) Furman B, Rawls HR, Wellinghoff S, Dixon H, Lankford J, Nicolella D. Metal-oxide nanoparticles for the reinforcement of dental restorative resins. Crit Rev Biomed Eng 2000; 28: 439-443.

28) Garcia IM, Leitune VCB, Samuel SMW, Collares FM. Influence of different calcium phosphates on an experimental adhesive resin. J Adhes Dent 2017; 21: 1-6.

29) Garcia IM, Leitune VC, Kist TL, Takimi A, Samuel SM, Collares FM. Quantum dots as nonagglomerated nanofillers for adhesive resins. J Dent Res 2016; 95: 1401-1407.

30) Karabela MM, Sideridou ID. Synthesis and study of physical properties of dental light-cured nanocomposites using different amounts of a urethane dimethacrylate trialkoxysilane coupling agent. Dent Mater 2011; 27: 1144-1152.

31) Mohsen NM, Craig RG. Effect of silanation of fillers on their dispersability by monomer systems. J Oral Rehabil 1995; 22: 183-189.

32) Espelid I, Tveit AB, Erickson RL, Keck SC, Glasspoole EA. Radiopacity of restorations and detection of secondary caries. Dent Mater 1991; 7: 114-117.

33) Collares FM, Ogliari FA, Zanchi CH, Petzhold CL, Piva $\mathrm{E}$, Samuel SM. Influence of 2-hydroxyethyl methacrylate concentration on polymer network of adhesive resin. J Adhes Dent 2011; 13: 125-129.

34) Ferracane JL. Correlation between hardness and degree of conversion during the setting reaction of unfilled dental restorative resins. Dent Mater 1985; 1: 11-14.

35) Faria-e-Silva AL, Lima AF, Moraes RR, Piva E, Martins LR. Degree of conversion of etch-and-rinse and self-etch adhesives light-cured using QTH or LED. Oper Dent 2010; 35: 649-654.

36) Gaglianone LA, Lima AF, Goncalves LS, Cavalcanti AN, Aguiar FH, Marchi GM. Mechanical properties and degree of conversion of etch-and-rinse and self-etch adhesive systems cured by a quartz tungsten halogen lamp and a light-emitting diode. J Mech Behav Biomed Mater 2012; 12: 139-143. 
37) Belli R, Kreppel S, Petschelt A, Hornberger H, Boccaccini AR, Lohbauer U. Strengthening of dental adhesives via particle reinforcement. J Mech Behav Biomed Mater 2014; 37: 100108.

38) Vlček J, Rezek J, Houška J, Čerstvý R, Bugyi R. Process stabilization and a significant enhancement of the deposition rate in reactive high-power impulse magnetron sputtering of $\mathrm{ZrO} 2$ and Ta2O5 films. Surf Coat Technol 2013; 236: 550556.

39) de Souza MO, Branco Leitune VC, Bohn PV, Werner Samuel SM, Collares FM. Physical-mechanical properties of BisEMA based root canal sealer with different fillers addition. J Conserv Dent 2015; 18: 227-231.

40) Altmann ASP, Collares FM, Balbinot GS, Leitune VCB,
Takimi AS, Samuel SMW. Niobium pentoxide phosphate invert glass as a mineralizing agent in an experimental orthodontic adhesive. Angle Orthod 2017; 87: 759-765.

41) Schneider LF, Moraes RR, Cavalcante LM, Sinhoreti MA, Correr-Sobrinho L, Consani S. Cross-link density evaluation through softening tests: effect of ethanol concentration. Dent Mater 2008; 24: 199-203.

42) Martins GC, Meier MM, Loguercio AD, Reis A, Gomes JC, Gomes OM. Effects of adding barium-borosilicate glass to a simplified etch-and-rinse adhesive on radiopacity and selected properties. J Adhes Dent 2014; 16: 107-114.

43) Lohbauer U, Belli R, Ferracane JL. Factors involved in mechanical fatigue degradation of dental resin composites. J Dent Res 2013; 92: 584-591. 